\title{
O REGISTRO E A DOCUMENTAÇÃO DO PATRIMÔNIO INDUSTRIAL NO BRÁS E NA MOOCA.
}

MANOELA ROSSINETTI RUFINONI, UNIVERSIDADE FEDERAL DE SÃO PAULO, GUARULHOS, SÃO PAULO, BRASIL

Arquiteta e urbanista pela Universidade Mackenzie, mestre e doutora pela FAU-USP. Docente do Departamento de História da Arte e do Programa de Pós-Graduação em História da Arte da Escola de Filosofia, Letras e Ciências Humanas da Unifesp.

Pesquisa elaborada com o auxílio da Fundação de Apoio à Unifesp (FAP-Unifesp). E-mail: mrr@usp.br.

DOI

http://dx.doi.org/10.11606/issn.1980-4466.v0iesp21p219-243 


\section{O REGISTRO E A DOCUMENTAÇÃO DO PATRIMÔNIO INDUSTRIAL NO BRÁS E NA MOOCA. \\ MANOELA ROSSINETTI RUFINONI}

\section{RESUMO}

O texto discorre sobre as iniciativas de registro do patrimônio arquitetônico da industrialização em áreas delimitadas nos bairros do Brás e da Mooca, na cidade de São Paulo, e as principais dificuldades relacionadas à documentação de bens patrimoniais na escala urbana. As experiências em pauta foram originadas de estudos e levantamentos realizados em âmbito acadêmico, iniciados em 2001, e de iniciativas de cooperação técnica entre a universidade e o poder público municipal, construídas com o intuito de viabilizar a elaboração de registros documentais do patrimônio urbano em áreas sujeitas a grandes transformações urbanísticas. A trajetória desses estudos e iniciativas evidenciou uma série de dificuldades, desde a necessidade de cunhar critérios e estratégias de registro capazes de abarcar as especificidades da escala urbana, até a constatação dos limites dos instrumentos de tutela para o tratamento desses bens. Tais iniciativas, contudo, ofereceram relevante contribuição para o aprimoramento dos instrumentos de registro e de documentação na escala urbana, além de buscar caminhos para uma maior interlocução entre os estudos acadêmicos e as práticas preservacionistas promovidas pelo poder público.

\section{PALAVRAS-CHAVE}

Patrimônio urbano. Brás. Mooca. Indústrias (Arquitetura). 


\section{REGISTERING AND DOCUMENTING THE INDUSTRIAL HERITAGE AT THE BRÁS AND MOOCA DISTRICTS. MANOELA ROSSINETTI RUFINONI}

\section{ABSTRACT}

This paper presents the processes of registration of the architectural industrial heritage in the districts of Brás and Mooca, in the city of São Paulo, and the main difficulties related to the documentation of urban cultural assets. The examples in question originated from studies and surveys conducted in the academic scope, started in 2001, and technical cooperation initiatives between the university and the municipal government, signed in order to facilitate the development of documentary records of urban heritage in areas that will be subject to large urban transformations. The trajectory of these studies and initiatives highlighted a number of difficulties, from the need of determining registration criteria and strategies to deal with the specificities of an urban scale, to the observation of public policies' limits in terms of protection of these assets. Such initiatives, however, significantly improved the recording and documenting instruments on urban scale, they also found ways to enhance the dialogue between academic studies and preservation practices promoted by the government.

\section{KEYWORDS}

Urban heritage. Brás District. Mooca District. Industry (Architecture). 
O período compreendido entre o final do século XIX e as primeiras décadas do século XX foi decisivo para a conformação da paisagem industrial em determinadas áreas da cidade de São Paulo (SP), como no Brás e na Mooca, bairros historicamente caracterizados pela origem fabril e operária, localizados a leste do centro da cidade, nas proximidades das vias férreas e da várzea do rio Tamanduateí. Atualmente, após décadas de transformações urbanas que conferiram à região novos potenciais de uso os antigos bairros operários ainda possuem diversos conjuntos edificados de significativo valor histórico e arquitetônico, provenientes de diferentes períodos de transformação ${ }^{1}$, fato que lhes confere particular interesse para os estudos de história urbana e social. Num traçado pautado pela alternância entre edifícios fabris, residências modestas e equipamentos diversos, a configuração espacial resultante e o dinamismo das ruas, de ontem e de hoje, ainda revelam uma intrincada rede urbana sistematicamente voltada para a atividade produtiva. A leitura das estratificações do tempo no desenho desses bairros, contudo, tem sido ameaçada pela rapidez e magnitude das transformações urbanas observadas em tempos recentes, processo que despontou já na década

1. Além de diversos edifícios tombados nos níveis municipal ou estadual. Para uma listagem dos bens tombados na região, consultar RODRIGUES, 2012. 
de 1960, quando o movimento de desconcentração industrial começou a afastar as atividades fabris da região.

Por esse motivo, a área compreendida entre os bairros do Brás e da Mooca tem sido alvo de recorrentes propostas de revitalização urbana, dentre as quais destacamos as operações urbanas atualmente em discussão na prefeitura municipal. A chamada operação urbana consorciada ${ }^{2}$, instrumento previsto em lei federal, objetiva promover transformações urbanísticas estruturais em áreas previamente delimitadas em planos diretores, com o intuito de criar instrumentos de valorização urbana e ambiental. Em São Paulo, parcelas urbanas lindeiras à linha 10 da Companhia Paulista de Trens Metropolitanos (CPTM), antiga ferrovia Santos-Jundiaí, integram o perímetro-alvo de futuras operações urbanas, segundo demarcações propostas pelos últimos Planos Diretores Estratégicos da cidade de São Paulo (PDE-SP) ${ }^{3}$.

A perspectiva de realização de grandes obras nessas regiões, portanto, tem impulsionado a necessidade de inventariar os bens arquitetônicos e urbanos ainda não identificados e convenientemente analisados, com o intuito de viabilizar estudos voltados ao reconhecimento e à proteção legal de alguns exemplares, visando a sua preservação e valorização.

\section{EXPERIÊNCIAS INICIAIS: A ESCALA URBANA NO FOCO DO MÉTODO}

Levantamentos realizados por órgãos da administração pública paulistana entre as décadas de 1970 e 1980 já indicavam a preocupação com a inventariação de bens culturais relacionados aos processos de industrialização. Ainda que o objetivo desses levantamentos não fosse, especifi-

\footnotetext{
2. BRASIL. Lei no. 10257, de 10 de julho de 2001. Estatuto da Cidade. Seção X, art. 32, §1. "Considera-se operação urbana consorciada o conjunto de intervenções e medidas coordenadas pelo Poder Público Municipal, com a participação dos proprietários, moradores, usuários permanentes e investidores privados, com o objetivo de alcançar em uma área transformações urbanísticas estruturais, melhorias sociais e valorização ambiental." (Grifo nosso).

3. Em 2010, a PMSP criou as Operações Urbanas Consorciadas Mooca-Vila Carioca (que abarca parte da antiga Diagonal Sul) e Lapa-Brás (que abarca trechos das operações Diagonal Norte, Diagonal Sul e Centro, e incorpora a totalidade da operação Água Branca). Em 2014, as operações foram redesenhadas e renomeadas. O perímetro que abarca os bairros do Brás e da Mooca passou a denominar-se Operação Urbana Bairros do Tamanduateí, segundo orientações do novo Plano Diretor Estratégico, aprovado pela Lei 16.050 de 31 de julho de 2014.
} 
camente, a catalogação dessa tipologia de bens, é imperioso ressaltar a presença de arquiteturas industriais entre os bens selecionados. $\mathrm{O}$ fato indica não somente a valorização desses artefatos como bens de interesse para preservação, mas, sobretudo, a gradativa assimilação de métodos de inventário que buscavam absorver a dimensão urbana da preservação incorporando avanços conceituais em âmbito internacional, como a ampliação do conceito de patrimônio cultural defendida pela Carta de Veneza, de 1964. As diretrizes emanadas em documentos internacionais voltados à preservação a partir da década de 1960 demarcam a constatação de que o patrimônio edificado compreende não apenas imóveis isolados, excepcionais, mas, sobretudo, os conjuntos construídos, os espaços e ambiências, assim como as dinâmicas urbanas e sociais ali abrigadas. Notamos, portanto, que a percepção da dimensão urbana da preservação caminhou lado a lado à valorização das manifestações edificadas da industrialização, diante da iminente ameaça de demolição a que estavam sujeitas naquele momento.

Na década de 1970, considerando a valorização de bens culturais em sua ambiência urbana, destacam-se os trabalhos da Coordenadoria Geral de Planejamento (COGEP), da Prefeitura Municipal de São Paulo (PMSP). O órgão iniciou, em 1974, um cadastramento de edificações e logradouros paulistanos com interesse para preservação, gerando as chamadas Z8-200. Inicialmente essas zonas foram demarcadas na área central da cidade, mas logo depois passaram a abranger parcelas de bairros que passavam por processos de renovação urbana, como a Zona Metrô-Leste, momento em que áreas de ocupação industrial chegaram a ser contempladas. ${ }^{4} \mathrm{Na}$ mesma época, por ocasião da implantação da linha Metrô-Leste, foi realizado um levantamento pela Divisão de Preservação, em conjunto com a COGEP, atendendo à socilitação da Companhia do Metrô. O estudo intitulado Patrimônio Ambiental Zona Metrô-Leste identificou diversos imóveis de interesse para preservação na área

\footnotetext{
4. As Z8-200 estavam sujeitas a medidas específicas estabelecidas na legislação de uso e ocupação do solo do município (Lei 8328/75). Entre os perímetros demarcados, muitos abarcavam áreas urbanas associadas à história da imigração, à estrada de ferro e à industrialização (Rodrigues, 2012, p.43). Como instrumento similar à Z8-200, atualmente adotamos as chamadas ZEPECs, Zonas Especiais de Preservação Cultural, definidas no PDE 2002.
} 
que seria atingida pelas obras do metrô, incluindo arquiteturas industriais (BAFFI, 2006, p. 169) . $^{5}$ Outro levantamento relevante foi realizado pela Empresa Municipal de Urbanização (Emurb), ainda na década de 1970. O volume Galpões industriais significativos objetivou estudar o uso do solo nos bairros do Brás e da Mooca, destacando aspectos urbanos considerados marcantes, como a presença de galpões industriais e vilas habitacionais, com o intuito de fundamentar futuros planos de reurbanização naquela região, impulsionados pelas obras do metrô. Foram listados 189 galpões industriais considerados representativos da ocupação urbana local, oriundos da primeira fase de industrialização paulistana, subdivididos em: galpões significativos; conjuntos industriais significativos; e áreas industriais significativas. A apresentação do levantamento sublinha seus objetivos:

O material recolhido permite observar que o Brás-Bresser e Mooca apresentam algumas áreas de intensa vitalidade urbana, ao lado de outras em franca deterioração. A ação conjunta dos diferentes órgãos públicos e da população interessada possibilitaria uma rápida melhoria das condições gerais de todo o bairro. O presente trabalho identifica os galpões industriais, conjuntos industriais significativos e áreas industriais significativas, objetivando oferecer insumo a entidaddes públicas e privadas para a criação de instrumentos adequados, capazes de guardar um pouco de nossa memória urbana e, ao mesmo tempo, encontrar caminhos para uma destinação dos espaços a serem reciclados (SÃO PAULO, 197[?]).

Na busca por um método de registro, está clara a preocupação em desenvolver instrumentos que ultrapasassem a ideia de edifício isolado, recorrente nos inventários arquitetônicos tradicionais. Na introdução, o documento esclarece que:

5. Segundo Rodrigues (2012, p.43-44), apesar de se tornar referência para estudos posteriores empreendidos pelo órgão municipal de preservação, este inventário não chegou a atingir o objetivo de preservar os bens indicados. A Companhia do Metrô também encomendou um levantamento similar para o tramo oeste da linha, estudo que abarcou 91 quadras nas imediações da via férrea entre os bairros da Lapa, Água Branca e Barra Funda. 
Tendo em vista as características de ocupação do Brás e os objetivos e competência desse trabalho, que visa uma abordagem da escala urbana e, portanto, das relações do edifício na malha urbana, os critérios pontuais tradicionais adotados para preservação de edifícios foram ultrapassados (SÃO PAULO, 197[?]).

O Inventário Geral do Patrimônio Ambiental, Cultural e Urbano de São Paulo (Igepac-SP), elaborado pela Secretaria Municipal de Cultura na década de 1980, também é apontado como uma importante iniciativa que buscou inverter o enfoque geralmente dado aos inventários patrimoniais, centrados no edifício considerado isoladamente. Segundo Castriota (2007), o Igepac-SP "tentava introduzir uma metodologia com abordagem especificamente urbana: em vez de listar-se os bens, partia-se de uma compreensão de unidades culturais mais amplas, áreas da cidade, que eram analisadas". Foram, ainda, objeto de inventariação, não apenas os bens ambientais urbanos consagrados como "monumentais", mas também conjuntos modestos, modos de organização do espaço e suas várias etapas de evolução (SÃO PAULO, 1987). O estudo empregou, ainda, instrumentos tradicionais de registro, como as fichas de inventário, mas buscou enfatizar análises urbanísticas das áreas catalogadas, comentando aspectos históricos e socioculturais. A metodologia adotada dividiu áreas urbanas maiores em subáreas com características próprias, ali localizando os bens culturais. Importante destacar que este inventário deixava de ser considerado um registro ou preparação para o tombamento e pretendia "participar nas políticas e planos de desenvolvimento urbano, no que diz respeito às áreas a serem preservadas e outras sujeitas à renovação urbana" (SÃO PAULO, 1987), objetivo respondido com a elaboração de propostas específicas de preservação e de regulação urbana. $\mathrm{Na}$ análise de Castriota (2007, p.74-75), a perspectiva urbanística adotada pelo Igepac-SP aproxima-se da expansão da ideia de patrimônio, mas não atinge satisfatoriamente o estudo de aspectos socioculturais: "falta ao Igepac-SP exatamente a abordagem daquela dimensão menos palpável da cultura, que está na base da construção social de identidades espaciais distintas, que, em última instância, permitem que cada setor da cidade seja percebido e representado de forma própria pela população”. 
Em âmbito acadêmico, as experiências de identificação e registro de edifícios fabris na cidade de São Paulo com vistas à preservação ganharam corpo, sobretudo, a partir dos anos 2000. Enfocaremos neste estudo as pesquisas diretamente relacionadas com o percurso de delineamento metodológico que aqui buscamos evidenciar. A pesquisa intitulada Preservação do patrimônio industrial na cidade de São Paulo: o bairro da Mooca centrou-se na identificação, registro e análise de um perímetro urbano de ocupação marcadamente industrial, datada do final do século XIX e início do século XX (RUFINONI, 2004). Na ocasião, a área enfocada integrava a operação urbana então denominada Diagonal Sul, cujos contornos e nomenclatura seriam redefinidos duas vezes nas gestões municipais seguintes, passando a denominar-se Mooca-Vila Carioca, em 2010, e Bairros do Tamanduateí, em 2014, segundo determinações do novo Plano Diretor.

Como cabe aos estudos acadêmicos, a pesquisa não objetivou a elaboração de um inventário detalhado, considerado isoladamente. O levantamento das edificações fabris foi elaborado como parte de um estudo mais amplo que buscou compreender os motivos pelos quais o conjunto urbano em pauta adquire representatividade como patrimônio cultural e os caminhos possíveis e desejáveis para sua tutela. Sendo assim, foram elaborados estudos sobre a importância patrimonial do complexo urbano, tecendo reflexões acerca das correlações históricas entre industrialização e urbanização na região e as repercussões desses processos na materialidade arquitetônica. Tais análises foram seguidas de estudos teóricos sobre a preservação do patrimônio histórico em geral e do patrimônio industrial em particular, buscando evidenciar quais particularidades históricas, estéticas e socioculturais estão envolvidas na atribuição de valores ao patrimônio de origem fabril. Em linhas gerais, no que tange ao método de pesquisa adotado, foram percorridas as seguintes etapas: 1. Estudos bibliográficos e documentais acerca da formação histórica da cidade e do bairro em questão; 2 . Análise de mapas históricos, buscando delimitar as parcelas de ocupação urbana mais antiga; 3. Verificação de levantamentos existentes elaborados pela administração pública municipal; 4. Delimitação da área de estudo e do período histórico a ser abordado, cruzando dados provenientes das pesquisas bibliográfica e de campo; 5 . Análise da situação atual, com base no estudo dos levantamentos realizados pelos Planos Diretores Regionais, datados de 
2003; 6. Levantamentos de campo para identificação e registro fotográfico; 7. Seleção das edificações e conjuntos fabris mais significativos; 8. Busca documental sobre as edificações selecionadas; 9. Elaboração de mapa síntese; e 10. Discussões teóricas sobre a preservação do patrimônio industrial, apontando diretrizes para a sua preservação.

Ao todo foram listados 19 edifícios ou conjuntos fabris, dentre os quais foram selecionados os mais significativos a serem analisados com maior atenção. Na sequência dessas observações, a pesquisa evidenciou a participação de renomados arquitetos na configuração deste cenário industrial. Além de Júlio Michele, autor do primeiro galpão da São Paulo Alpargatas e Giovanni Battista Bianchi, responsável pelo edifício da fiação do Cotonifício Crespi, ambos arquitetos italianos referenciados na bibliografia analisada (SALMONI; DEBENEDETTI, 1981), a pesquisa trouxe à tona a participação do escritório de Ramos de Azevedo e Ricardo Severo, autores do projeto dos Armazéns Ernesto de Castro e também de Victor Dubugras, autor do projeto dos Armazéns Gerais Piratininga.

$\mathrm{O}$ processo de pesquisa evidenciou uma série de dificuldades diretamente relacionadas à escala urbana que esse tipo de patrimônio necessariamente envolve. As dificuldades iniciaram-se no próprio processo de registro, pois que foi necessário lidar com características morfológicas peculiares, quadras e lotes de grandes dimensões e especificidades funcionais que extrapolam o limite de cada propriedade. Na sequência das investigações sobre as alternativas de tutela desses bens, deparamo-nos com os limites do instrumento de tombamento, originalmente pensado para tutelar edifícios isolados. Partindo das limitações do tombamento, notamos a dificuldade de justificar a preservação de elementos desse complexo urbano, partes não necessariamente excepcionais, com o intuito de apreender as especificidades de conjunto: as correlações entre edifícios, sistemas de transporte, pátios logísticos e conjuntos urbanos envoltórios, laços que nos permitiriam compreender os processos de formação histórica e de construção de sociabilidades em torno da atividade fabril. A grande dimensão dos edifícios e lotes, por sua vez, também é um dos motivos que mais os ameaçam de demolição, já que se tornam atrativos para novos empreendimentos imobiliários que veem na região um importante nicho de mercado. 
Com relação aos instrumentos jurídicos voltados à preservação de bens urbano-arquitetônicos, é notória a referência ao tema na elaboração nos últimos Planos Diretores do Município de São Paulo, a partir da criação das Zonas de Preservação Cultural, áreas urbanas demarcadas em lei e que passam a ser estudadas para possível tombamento. ${ }^{6}$ Se nos ativermos ao Plano Diretor de 2002 (Lei 13430/2002), em vigor na época em que os estudos aqui descritos foram realizados, são significativas as zonas demarcadas que abarcam áreas de ocupação industrial. Essa seleção contou, inclusive, com a participação popular, promovendo a demarcação de artefatos representativos de diferenciadas experiências cotidianas e memórias urbanas: galpões industriais, estações ferroviárias, conjuntos de casas e vilas, travessias metálicas sobre a estrada de ferro etc. A ZEPEC, no entanto, é um instrumento jurídico geralmente empregado para a preservação de lotes considerados individualmente, sendo difícil justificar a preservação de vários lotes contíguos na intenção de abranger um perímetro significativo. Por esse motivo, como repercussão dos levantamentos realizados na pesquisa citada (RUFINONI, 2004), em 2006 foi encaminhado um pedido de tombamento que sugeria a inclusão de todos os edifícios de interesse histórico e estético evidenciados na pesquisa e que não haviam sido demarcados como ZEPEC pelo Plano Diretor então em vigor ${ }^{7}$. O pedido de tombamento procurou garantir a integridade do complexo urbano, já que a preservação apenas de edifícios isolados não seria suficiente para preservar as

6. Segundo o Plano Diretor então em vigor (Lei no. 13.430/2002, artigo 168), “as Zonas de Preservação Cultural - ZEPEC são porções do território destinadas à preservação, recuperação e manutenção do patrimônio histórico, artístico e arqueológico, podendo se configurar como sítios, edifícios ou conjuntos urbanos." No novo Plano Diretor aprovado em 2014, as ZEPECs são definidas como "porções do território destinadas à preservação, valorização e salvaguarda dos bens de valor histórico, artístico, arquitetônico, arqueológico e paisagístico, doravante definidos como patrimônio cultural, podendo se configurar como elementos construídos, edificações e suas respectivas áreas ou lotes; conjuntos arquitetônicos, sítios urbanos ou rurais; sítios arqueológicos, áreas indígenas, espaços públicos; templos religiosos, elementos paisagísticos; conjuntos urbanos, espaços e estruturas que dão suporte ao patrimônio imaterial e/ou a usos de valor socialmente atribuído." (Lei no. 16.050/2014, art. 61).

7. São Paulo (Cidade). CONPRESP. Processo de Tombamento n. 2006 - 0.111.388-4. 
características da paisagem (RUFINONI, 2013b) ${ }^{8}$. Os edifícios listados em 2006 não chegaram a ser tombados, mas o pedido reforçou a necessidade de se tutelar ao menos os edifícios demarcados como ZEPEC, finalmente tombados em 2007. Proveniente deste zoneamento ZEPEC, foram tombados vários edifícios que compõem um significativo conjunto industrial ao longo da Rua Borges de Figueiredo, bem como definidos critérios específicos de ocupação no entorno imediato. $\mathrm{O}$ tombamento foi resultado de estudos pormenorizados realizados pelo órgão municipal, enfocando não apenas o valor histórico dos bens, mas, sobretudo, as relações com o entorno e a ambiência características da região, elementos que levaram à delimitação de restrições de gabarito para as novas construções num perímetro envoltório determinado pela resolução de tombamento (São Paulo, 2007 e 2007b). ${ }^{9}$ Nos anos seguintes, em 2010 e em 2012, outros remanescentes de estruturas industriais foram protegidos no mesmo perímetro ${ }^{10}$, concluindo um relevante episódio na história da preservação de bens industriais na cidade de São Paulo.

Como desdobramento da experiência de pesquisa no bairro da Mooca - e percebendo a dinâmica de transformação em curso, sobretudo diante das possibilidades de transformação anunciadas pelas

8. O pedido de tombamento agrupou os edifícios em duas categorias: edifícios de especial relevância e edifícios que compõem a paisagem industrial do bairro. Além de agrupar edifícios que, isoladamente, não seriam considerados de interesse para preservação, solicitamos atenção especial ao entorno, área que preserva as características da ocupação industrial do início do século XX (RUFINONI, 2013b).

9. Procurou-se proteger não apenas edifícios isolados, mas todo um conjunto arquitetônico homogêneo e representativo de etapas decisivas na formação urbana do bairro e da cidade. A Resolução CONPRESP 14/07 determinou o tombamento do conjunto de galpões das Oficinas Vanorden; o Moinho Minetti Gamba; o conjunto de depósitos para armazenagem de café posteriormente adquiridos pela CEAGESP; o conjunto arquitetônico da Sociedade Técnica Bremensis e Schmidt Trost e os armazéns da antiga São Paulo Railway. O tombamento abrange o perímetro formado pelas ruas Borges de Figueiredo, Monsenhor João Felipo, avenida Presidente Wilson e viaduto São Carlos e determina, ainda, restrições de gabarito no entorno. As alturas das novas construções deverão ser estudadas caso a caso, não ultrapassando, porém, $25 \mathrm{~m}$ nas áreas adjacentes aos imóveis tombados e $30 \mathrm{~m}$ nos quarteirões entre a rua Borges de Figueiredo e a rua João Antonio de Oliveira, que também não poderão ser remembrados (RUFINONI, 2013a, p.284).

10. Em 2010, foi tombada a chaminé da antiga Companhia União de Refinadores, encerrando processo aberto em 2008 (Res. 05/10). Anos depois, em 2012, foi homologado o tombamento de edificações remanescentes do antigo conjunto das Indústrias Reunidas Francisco Matarazzo, complexo que também abrigou a fábrica de Fósforos Fiat Lux, a Fábrica da Duchen e um ramal ferroviário (RODRIGUES, 2012, p.50). 
operações urbanas -, demos prosseguimento à pesquisa buscando alicerçar, justamente, a compreensão do caráter urbano do patrimônio da industrialização e a necessidade de desenvolver um debate que partisse dessa constatação para subsidiar ações de transformação e intervenção. Nos estudos subsequentes, aprofundamos a investigação sobre a dimensão urbana da preservação, abordando as intervenções na grande escala como projetos de restauro urbano (RUFINONI, 2013a). Buscou-se discutir a aplicabilidade dos princípios teóricos da preservação e do restauro na prática de intervenções no patrimônio urbano industrial, evidenciando, por um lado, os percursos investigativos e cognitivos que concorreram para o amadurecimento de conceitos, teorias e princípios em torno da preservação e do restauro do patrimônio urbano e; por outro, os principais problemas enfrentados no tratamento dos sítios industriais de interesse cultural. Nesse percurso de investigação, demos prosseguimento ao levantamento de edifícios e sítios industriais no perímetro abarcado pela operação urbana, totalizando 62 edifícios. Listagem, porém, seguramente incompleta (RUFINONI, 2013a, p.282283). Certamente, a pesquisa não objetivou mapear todos os conjuntos industriais existentes no extenso perímetro da operação urbana. O mapeamento, contudo, buscou reforçar graficamente a grande extensão urbana que ainda precisamos inventariar, reforçando o argumento central da discussão, a questão da escala urbana da preservação e dos meios e métodos adequados para nela intervir.

\section{APREENSÃO E REGISTRO DO PATRIMÔNIO URBANO INDUSTRIAL: ALGUMAS DIFICULDADES}

Em ambas as experiências descritas, assim como nos levantamentos realizados pela administração pública entre as décadas de 1970 e 1980, as particularidades do patrimônio da industrialização ofereceram significativos entraves para a efetivação de registros e de documentação apropriada que pudesse suprir demandas de preservação ou, mesmo, como já apontavam os trabalhos da Cogep e da Emurb, subsidiar futuras intervenções urbanas de revitalização.

Entre as dificuldades encontradas, a questão da escala urbana emerge em primeiro plano. Na elaboração de levantamentos e inventários, a 
extensão da ocupação industrial impõe limitações tanto de ordem prática - dificultando a apreensão do conjunto, os percursos a serem percorridos e a análise da documentação arquivística, geralmente dispersa ou em posse de particulares pouco sensíveis às pesquisas no campo da preservação -, como também analíticas, relacionadas à dificuldade de perceber, avaliar e mapear as transformações funcionais, as novas dinâmicas urbanas e os modos de vivenciar esses espaços. Se, por um lado, os bairros industriais mantêm certa homogeneidade na configuração da paisagem, por outro, dada a grande extensão envolvida, há que se considerar significativas particularidades em diferentes parcelas de cada bairro, devido às distâncias exercidas, aos grandes lotes e às rupturas no tecido social dentro de um mesmo bairro.

Soma-se a essas problemáticas a já citada pressão da atividade imobiliária que tem se expandido significativamente em todo o perímetro da operação urbana, causando demolições e transformando a paisagem com grande rapidez. Nesse contexto de relevantes transformações, surge a dificuldade de identificar, nos elementos remanescentes, as relações urbanas, sociais e memoriais ainda mantidas com as atividades anteriormente sediadas, ou seja, a leitura da estratificação histórica para além da materialidade, buscando perceber, na dinâmica dos usos e vocações atuais, pontos de contato com as atividades passadas, não necessariamente na manutenção de funções fabris, mas na ambiência característica que induz determinadas formas de apropriação e leitura coletiva desses espaços. Outra questão subjacente é a relação estabelecida entre os moradores e usuários dessas regiões, a conformação de espaços de sociabilidade e a compatibilização com novas dinâmicas urbanas e vocações funcionais, certamente desejadas.

A variedade de questões aqui brevemente expostas evidencia a necessidade de envolvermos equipes multidisciplinares nas ações de preservação, observação que alude aos diversos elementos envolvidos na configuração de determinados monumentos, conforme a nova abrangência do termo contemplada em documentos internacionais, como a Carta de Veneza, em seu artigo segundo, bem como a Declaração de Amsterdã e a Carta de Washington.

As dificuldades relacionadas aos métodos de inventário possuem estreitos paralelos com os entraves relacionados à aplicação dos 
instrumentos de tutela e de planejamento urbano, em áreas dessa natureza. Conforme aludimos, o tombamento que considera um edifício isoladamente não é capaz de abarcar todas as especificidades desejadas do patrimônio da industrialização, e as iniciativas advindas do campo do planejamento, a exemplo das ZEPECs, ainda não se configuram como caminhos de preservação autônomos ao tombamento, pois, como vimos, apenas demarcam áreas que posteriormente serão estudadas com vistas ao tombamento, recaindo, portanto, no mesmo instrumento.

O primeiro passo, para qualquer operação na área abarcada pela operação urbana, seria a elaboração de estudos detalhados sobre todo o perímetro, de pesquisas aprofundadas sobre o processo de urbanização local, sobre as edificações existentes, suas características construtivas formais e técnicas, acompanhadas de estudos multidisciplinares que permitissem a apreensão das diversas e complexas relações materiais e imateriais que definem essa paisagem. A realização desses estudos pormenorizados permitiria que apreendêssemos com clareza os elementos que definem essa paisagem, quais os edifícios e conjuntos que devem ser efetivamente preservados e de que maneira. Conhecimento prévio, portanto, imprescindível para a proposição e execução de quaisquer projetos de revitalização. A questão que se coloca no âmbito da prática de inventário é, justamente, como depurar essas necessidades e prerrogativas num método capaz de abarcar tantas especificidades, num procedimento que ultrapasse as limitações dos inventários tradicionais, geralmente baseados nas fichas de identificação mais atreladas aos aspectos materiais do bem, considerados isoladamente. Diante de tantas particularidades, como inventariar, o quê inventariar e como apresentar os dados? Considerando, ainda, a apreensão das dinâmicas urbanas em suas especificidades materiais e imateriais, amalgamadas e nunca excludentes, como poderíamos inserir, na inventariação do patrimônio urbano, aspectos relacionados à caracterização sociocultural e à vida das ruas, ou seja, àquela "dimensão menos palpável da vida urbana e da cultura que está na base da construção social de identidades espaciais distintas", conforme exposto por Castriota (2007, p.75)? As experiências que se seguem, certamente, não lograram responder a todas essas perguntas, mas acreditamos ter oferecido uma significativa contribuição 
para o prosseguimento deste debate e para uma aproximação, desejada e necessária, entre as iniciativas advindas das universidades e as práticas promovidas pelo poder público no campo do patrimônio cultural.

\section{PATRIMÔNIO EDIFICADO NOS BAIRROS DO BRÁS E DA MOOCA: INVENTÁRIO E INVESTIGAÇÃO}

O projeto intitulado Patrimônio edificado no Brás e na Mooca surgiu a partir de tratativas entre pesquisadores envolvidos com a temática provenientes da Faculdade de Arquitetura e Urbanismo da Universidade de São Paulo (FAU-USP) e da Escola de Filosofia, Letras e Ciências Humanas da Universidade Federal de São Paulo (EFLCH-Unifesp) -, e a equipe técnica do Departamento do Patrimônio Histórico da Prefeitura Municipal de São Paulo (DPH-PMSP), órgão interessado em realizar pesquisas conjuntas com a universidade como instrumento para viabilizar estudos voltados à preservação de bens culturais. As pesquisas resultantes dessa iniciativa foram realizadas entre 2012 e 2016.

O intuito do acordo de cooperação técnica foi fornecer bases teóricas e fundamentos documentais sobre o patrimônio existente em parcelas urbanas que integram o extenso perímetro objeto de futuras operações urbanas; áreas que deverão passar, portanto, por profundas transformações urbanísticas. Nesse contexto, o projeto teve por intuito identificar e caracterizar edificações que possam ser de interesse para preservação na área escolhida, oferecendo subsídios para a elaboração de inventários e para políticas públicas de preservação.

A cooperação técnica, portanto, buscou atingir dois objetivos principais: de um lado, contribuir para a realização de levantamentos que subsidiarão futuros estudos de tombamento empreendidos pelo DPH-PMSP; e de outro, iniciar os estudantes da FAU-USP e da EFLCH-Unifesp na prática científica associada à realização de inventários do patrimônio cultural, desde a pesquisa histórica e documental até os levantamentos de campo, colocando-os em contato com diferentes fontes documentais e com os desafios interpretativos próprios da prática de pesquisa, uma importante contribuição para a formação intelectual e científica de futuros pesquisadores.

$\mathrm{O}$ projeto articulou pesquisas de Iniciação Científica propostas conjuntamente, através de grupos de estudo da FAU-USP (voltados ao 
estudo do bairro do Brás) e da Unifesp (voltados ao estudo do bairro da Mooca), coordenados respectivamente pelas profas. Dras. Beatriz $\mathrm{Mu}-$ gayar Kühl e Manoela Rossinetti Rufinoni. As investigações tiveram uma base comum, pois os estudos bibliográficos para a compreensão dessa parte da cidade são os mesmos, mas cada estudante envolvido no projeto se dedicou a uma subárea específica. Desse modo, os projetos de pesquisa tiveram o mesmo núcleo teórico e propositivo no que diz respeito à justificativa, à bibliografia fundamental e ao método, mas cada estudante arcou com as especificidades de sua área de estudo.

Do ponto de vista da administração municipal, as pesquisas propostas caminhariam no sentido de fomentar o conhecimento e a complementação de informações relativas ao expressivo patrimônio arquitetônico e ambiental urbano desses bairros, de modo a atingir os seguintes objetivos:

- Cooperação com instituições universitárias contribuindo com a formação acadêmica, o desenvolvimento de pesquisas e o aperfeiçoamento institucional e técnico do DPH;

- Organização de um inventário preliminar de bens arquitetônicos e ambientais desses bairros, integrando-o ao sistema de informações públicas sobre bens culturais paulistanos do DPH e da Secretaria Municipal de Cultura;

- Seleção e indicação de exemplares de maior significado desse conjunto de bens para possível reconhecimento e proteção legal visando sua preservação e valorização;

- Subsídios a planos urbanísticos de revitalização desses bairros, com destaque para a Operação Urbana Brás-Mooca, em desenvolvimento sob coordenação da SP-Urbanismo e da Secretaria Municipal de Desenvolvimento Urbano (SMDU);

- Aperfeiçoamento metodológico das ações de identificação de bens culturais;

- Valorização desse patrimônio cultural, perante a sociedade, através da possível difusão e divulgação dos resultados dessas pesquisas. ${ }^{11}$

11. SÃO PAULO (Cidade). Prefeitura Municipal de São Paulo. Ofício Ofício nº 070 / DPH.G / 2012. Ref:: Cooperação técnica para realização de inventários de bens culturais - Brás e Mooca. 
Por tratar-se de região extensa, a Diretoria da Divisão de Preservação propôs duas áreas de interesse para pesquisa nos bairros do Brás e da Mooca, considerando as intervenções que vêm acontecendo na área, com a demolição de grandes galpões e fábricas para a construção de condomínios residenciais.

Os perímetros propostos englobam, sobretudo, lotes de antiga ocupação fabril, concentrando extensas parcelas urbanas atualmente subutilizadas ou degradadas devido ao processo de desconcentração industrial observado na capital paulista a partir da década de 1970.

Os bairros do Brás e da Mooca passaram por vultosas transformações a partir do último quartel do século XIX, em especial devido à expansão da atividade industrial. Desse modo, as análises realizadas procuraram identificar os elementos estruturadores da área de estudo, procurando evidenciar o papel das unidades industriais, das habitações, de estruturas de ensino, religiosas, culturais, de lazer e de comércio, nesse processo. Para nortear nossas ações, empregamos a definição de patrimônio industrial defendida pela Carta de Nizhny Tagil, de 2003:

O patrimônio industrial compreende os vestígios da cultura industrial que possuem valor histórico, tecnológico, social, arquitetônico ou científico. Estes vestígios englobam edifícios e maquinaria, oficinas, fábricas, minas e locais de processamento e de refinação, entrepostos e armazéns, centros de produção, transmissão e utilização de energia, meios de transporte e todas as suas estruturas e infraestruturas, assim como os locais onde se desenvolveram atividades sociais relacionadas com a indústria, tais como habitações, locais de culto ou de educação.

O estudo foi desenvolvido através de pesquisa bibliográfica, pesquisa documental e iconográfica - explorando, em especial, plantas da cidade de São Paulo para acompanhar a transformação da área ao longo do tempo, pesquisas documentais em acervos públicos e pesquisa de campo, com a realização de registros fotográficos e capturas de imagens do serviço eletrônico Google Street View. 
FIGURA 1

Perímetro de estudo: Brás (São

Paulo, 2012).
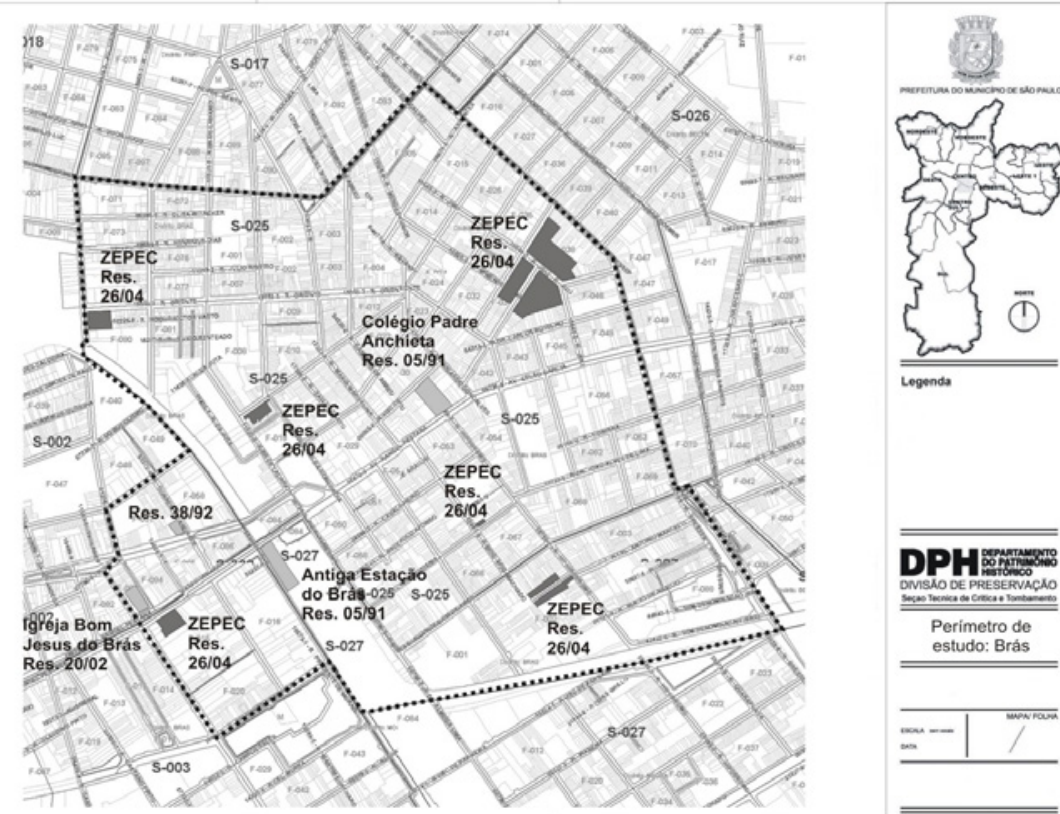

Perimetro de

estudo: Brás

\begin{tabular}{l|l}
$-\infty$ & 1 \\
\hline
\end{tabular}

FIGURA 2

Perímetro de estudo: Mooca (São

Paulo, 2012).

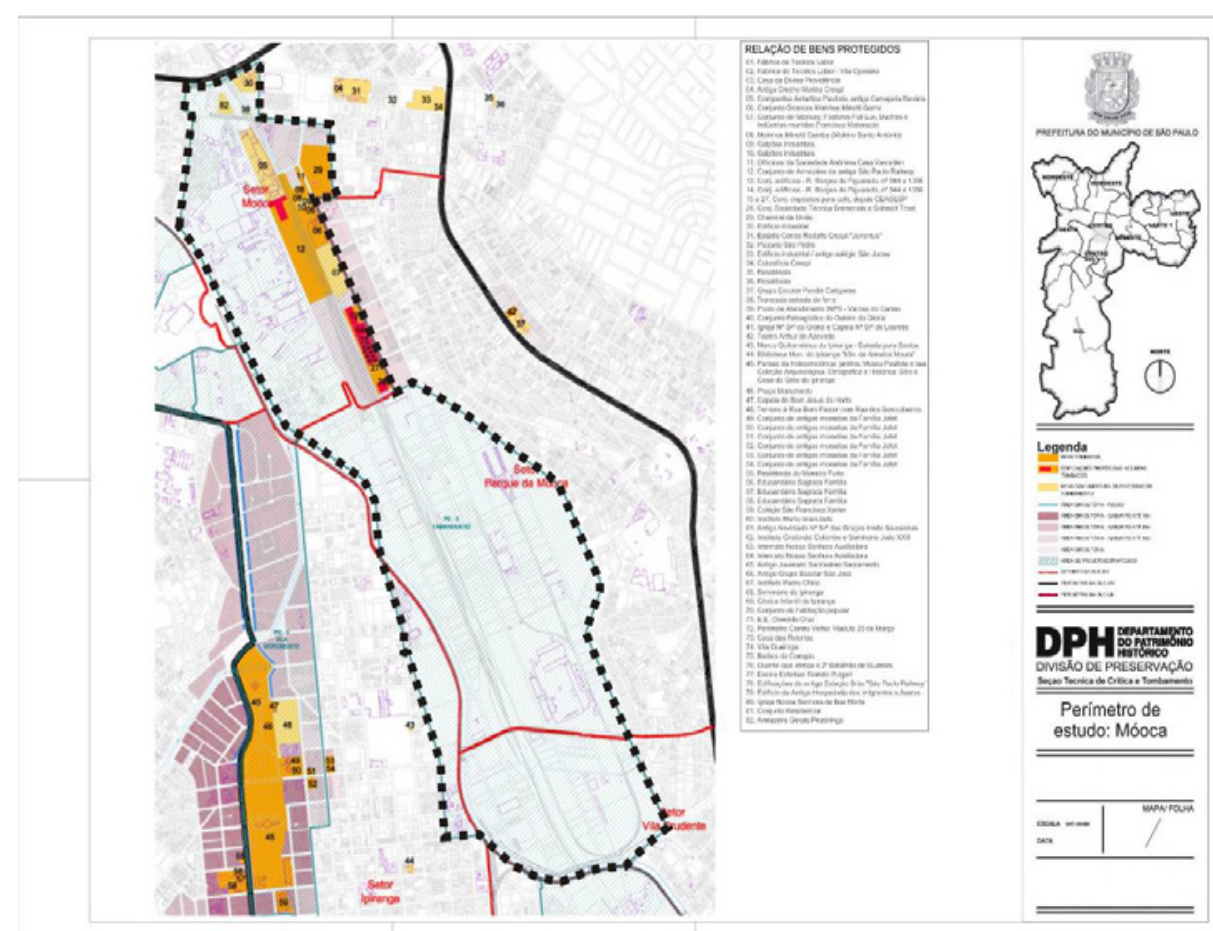




\section{MÉTODOS DE REGISTRO E DOCUMENTAÇÃO}

Sobre o percurso de pesquisa em ambas as equipes, a metodologia de investigação seguiu critérios semelhantes, adaptando algumas etapas devido às diferenças morfológicas entre as áreas enfocadas. Na parcela do perímetro Mooca mais próxima do perímetro Brás, considerando apenas as àreas à leste da via férrea, entre a avenida Alcântara Machado e o viaduto São Carlos, a morfologia urbana de ambos os perímetros é bastante similar. Há alguns lotes industriais de maiores dimensões, mas, em geral, o parcelamento urbano não apresenta quarteirões muito extensos e é significativa a presença de lotes de menores dimensões, ocupados por residências ou equipamentos comerciais, intecalados às áreas de ocupação fabril, ainda funcionais ou não. Já no restante do perímetro Mooca, contudo, considerando as parcelas à oeste da via férrea e toda a área além do viaduto São Carlos, notamos uma ocupação industrial mais recente, posterior à decada de 1940. Ali observamos um parcelamento do solo bastante distinto do Brás, com quarteirões e conjuntos industriais de dimensões muito maiores, dificultando sobremaneira a realização de estudos pormenorizados, desde os levantamentos documentais e de campo, até a elaboração de recursos gráficos para a visualização do conjunto. Dessa forma, os resultados obtidos no perímetro Brás puderam fornecer, ao lado da visão de conjunto, dados e análises mais pontuais - como o estudo de edifícios específicos, elaboração de mapas de identificação das edificações mais relevantes, dos imóveis tombados, de uso e ocupação do solo, além de perfis detalhados de alguns quarteirões, promovendo análises de volumetrias e gabaritos; ao passo que, no perímetro Mooca, buscamos desenvolver métodos de registro que permitissem a visualização da extensão do conjunto, atentando para elementos definidores da paisagem urbana e situações de particular interesse.

A equipe Mooca foi composta por quatro alunos de Iniciação Científica do curso de História da Arte da EFLCH-Unifesp, financiados pela Fundação de Apoio à Unifesp (FAP-Unifesp), entre 2012 e $2013^{12}$. A equipe Brás foi composta por sete alunos do curso de Arquitetura e Urbanismo da FAU-USP, dois financiados pela Fundação de Amparo à Pesquisa

12. Bolsistas Fap-Unifesp entre 2012 e 2013: Anne Caroline Pereira Mariano, Bruna Aparecida Silva de Assis, Elisabeth Costa Marcolino e Gabriela Rabello dos Santos. 
do Estado de São Paulo (Fapesp) e cinco pelo Conselho Nacional de Desenvolvimento Científico e Tecnológico (CNPq), entre 2012 e $2016^{13}$.

Em ambos os perímetros, a metodologia adotada seguiu três caminhos fundamentais, apresentando variações na forma de apresentação dos resultados, dependendo das especifidades de cada subárea em estudo: i) pesquisa bibliográfica e cartográfica; ii) pesquisa de fontes primárias e iii) pesquisa de campo. A pesquisa bibliográfica esteve pautada por leituras que tratassem da história da cidade de São Paulo, notadamente entre os séculos XIX e XX, e da formação dos bairros em análise, nesse contexto $^{14}$. Na sistematização dos dados coletados nesses estudos, buscou-se destacar as citações referentes aos bairros em análise nas principais referências bibliográficas, elaborando tabelas que indicam quais edifícios, equipamentos ou logradouros foram especificamente citados em cada leitura. Outra vertente de estudos bibliográficos voltou-se à análise de textos recentes sobre a preservação do patrimônio industrial na cidade de São Paulo, com foco nos bairros em análise ${ }^{15}$. Em seguida, foram realizados estudos da cartografia histórica de São Paulo, apontando as transformações observáveis nas áreas de estudo ao longo do tempo ${ }^{16}$. Paralelamente à pesquisa bibliográfica, foi iniciada a pesquisa de fontes primárias, na procura por documentação, mapas e imagens que tratassem dos bairros em estudo. Entre os acervos consultados, destacam-se as pesquisas na sede

13. Bolsistas de agosto de 2012 a julho de 2013: Bruna Dedini, Gabriela Piccinini e Renata Campiotto (bolsistas Pibic-CNPq) e Martha D. Bucci (bolsista FAPESP). Bolsistas de agosto de 2013 a julho de 2014: Yasmin Darviche, Tarsila Andrioli (respectivamente com bolsa Pibic-CNPq e Bolsa Santander).

14. As referências bibliográficas consultadas são extensas. Sobre o processo de formação e transformação da cidade de São Paulo, destacamos as obras de Alfredo Moreira Pinto, Antônio Bandeira Júnior, Juergen Richard Langenbuch, Richard Morse, Benedito Lima de Toledo, Warren Dean e Ernani Silva Bruno. Entre os estudos específicos sobre a formação dos bairros, citamos Maria Celestina Torres, Maria Margarida de Andrade e Manoela Rossinetti Rufinoni. Também foram consultados autores memorialistas, dentre os quais Mino Carta e Zélia Gattai.

15. Sobre a preservação do patrimônio arquitetônico e urbano, foram consultadas as obras de Gustavo Giovannoni Françise Choay, Beatriz Mugayar Kühl, Manoela Rufinoni, entre outros.

16. Foram pesquisados comparativamente vários mapas de São Paulo, analisando a região em estudo, entre eles os relativos aos anos de 1881; 1895; 1905; 1913; 1916; 1924; 1943; 1951; 1952, consultados nos acervos da Secretaria de Estado de Economia e Planejamento, Instituto Geográfico e Cartográfico. Além das bases cartográficas Sara-Brasil, de 1930; VASP Cruzeiro, de 1954; Sistema Cartográfico Metropolitano da Grande São Paulo (GEGRAN), de 1974 e o Levantamento Aerofotométrico da Emplasa, de 1981, consultados na Biblioteca da FAU-USP. As análises foram acompanhadas de estudos comparativos da situação atual, a partir das ferramentas Google Maps e Google Earth. 
do Departamento de Patrimônio Histórico de São Paulo (DPH-PMSP), em busca de estudos e levantamentos elaborados pela administração pública, além de consultas ao acervo iconográfico da Casa da Imagem e ao Arquivo Histórico Municipal. Além dessa documentação, foi consultado, no Conpresp e no Condephaat, os processos de tombamento que abarcam imóveis presentes nas áreas de estudo, possibilitando o conhecimento dos bens tombados, assim como as considerações quanto ao tombamento e a legislação aplicada a cada imóvel. ${ }^{17}$ Com o amadurecimento da pesquisa bibliográfica e de fontes primárias, deu-se início às atividades do levantamento de campo, gerando diferentes produtos gráficos em cada subárea ${ }^{18}$.

No perímetro Mooca, dada a grande extensão da área, primeiramente foi feita uma visita em grupo, percorrendo o perímetro do projeto para o reconhecimento da área. Notamos nessa visita que o perímetro era demasiado extenso, cabendo à equipe o desenvolvimento de um método de divisão da área que fosse eficaz para a pesquisa e depois para a organização das informações coletadas. Como a área mostrou-se extensa e pouco segura para percursos a pé e realização de fotografias, o levantamento foi realizado através da captura de imagens selecionadas no Google Maps e no Google Street View. A organização dos dados baseou-se em fotografias aéreas de cada rua percorrida, seguidas de perspectivas do início e do final da rua, bem como de imagens das fachadas dos imóveis considerados pela equipe como de possível interesse para preservação. A captura de imagens e organização dos dados coletados num único arquivo final baseou-se na delimitação de subperímetros nomeados por letras e demarcados com cores diferentes. Devido à grande extensão do perímetro e das quadras, buscou-se desenvolver métodos de registro que partissem do geral para o particular, ou seja, de uma visualização ampla da área abordada para as situações pontuais, em movimentos de aproximação em alternância de escalas. O intuito foi permitir a percepção das ambiências urbanas, da perspectiva do pedestre e das relações entre diferentes tipologias arquitetônicas (edifícios fabris,

17. A equipe Mooca não realizou pesquisas de processos de tombamento no CONDEPHAAT, pois, até 2012, não foram homologados tombamentos de edifícios industriais no perímetro em análise.

18. Os relatórios finais das pesquisas desenvolvidas foram entregues ao DPH-PMSP em formato eletrônico. 
residenciais, comercias etc.). Após o mapeamento geral do perímetro Mooca, iniciaram-se novas pesquisas voltadas a situações e temas específicos, a exemplo do levantamento e estudo das vilas e casas em série em subárea demarcada nas proximidades da Companhia Antártica Paulista; e a identificação e análise dos antigos cinemas de rua nos bairros do Brás e da Mooca, estudos elaborados entre 2014 e $2015^{19}$.

Apesar das limitações encontradas ao longo da execução do projeto - sobretudo relacionadas à grande extensão dos perímetros, à dificuldade de acesso às unidades fabris e aos problemas de segurança enfrentados pelos membros da equipe -, os resultados reunidos tiveram o intuito de registrar edificações e paisagens urbanas que hoje passam por incisivas transformações, na esperança de fornecer subsídios para futuros estudos e políticas públicas de preservação.

\section{AGRADECIMENTOS}

O desenvolvimento deste projeto contou com bolsas de Iniciação Científica fornecidas pela Fundação de Apoio à Unifesp (FAP-Unifesp), Fundação de Amparo à Pesquisa do Estado de São Paulo (Fapesp), Conselho Nacional de Desenvolvimento Científico e Tecnológico (PIBIC-CNPq) e Santander. Agradecemos, ainda, à equipe do DPH-PMSP, à Agradecemos, ainda, à equipe do DPH-PMSP, à orientadora das pesquisas de Iniciação Científica sediadas na FAU-USP, profa. Dra. Beatriz Mugayar, e a todas as alunas envolvidas: Luiza do Carmo Marcos Di Girolamo Nadalutti, Yasmin Darviche, Tarsila Andriole de Sousa, Renata Cima Campiotto, Bruna Dedini Silva, Gabriela Mascarenhas Piccinini e Martha Dallari Bucci, na FAU-USP; e Anne Caroline Pereira Mariano, Bruna Aparecida Silva de Assis, Elisabeth Costa Marcolino e Gabriela Rabello dos Santos, na EFLCH-Unifesp.

19. Pesquisas realizadas pelas alunas Gabriela Rabello dos Santos: Vilas e casas em série no bairro da Mooca: patrimônio urbano paulistano, Monografia de Conclusão de Curso apresentada à EFLCH-Unifesp em 2014; e Bruna Aparecida Silva de Assis: As antigas salas de cinema nos bairros do Brás e da Mooca: arquiteturas e espaços de sociabilidade, pesquisa de Iniciação Científica financiada pela Fapesp, concluída em 2015. 


\section{REFERÊNCIAS}

BAFFI, Mirthes O IGEPAC-SP e outros inventários da Divisão de Preservação do DPH: um balanço. Revista do Arquivo Municipal, São Paulo, v. 204, p. 169-191, 2006.

BRASIL. Lei n. 10257, de 10 de julho de 2001. Estatuto da Cidade.

Carta de Nizhny Tagil sobre o patrimônio industrial. The International Committee for the Conservation of the Industrial Heritage (TICCIH), Julho 2003.

CASTRIOTA, Leonardo. Inventários como instrumentos de preservação. In: LIMA, E. F. W. e MALEQUE, M. R. Espaço e Cidade: conceitos e leituras. Rio de Janeiro: 7 Letras, 2007.

RODRIGUES, Angela Rosch. Patrimônio industrial e os órgãos de preservação na cidade de São Paulo. Revista CPC, São Paulo, n.14, maio 2012/out. 2012.

RUFINONI, M. R. Preservação do patrimônio industrial na cidade de São Paulo: o bairro da Mooca. Dissertação de Mestrado. São Paulo: FAUUSP, 2004.

. Preservação e restauro urbano: intervenções em sítios históricos industriais. São Paulo: Fap-Unifesp, Edusp, Fapesp. 2013a.

. Descrizioni e omissioni nella preservazione del patrimonio urbano industriale: un caso studio a São Paulo / Brasile. In: VI Congresso AISU Associazione Italiana di Storia Urbana. Visibile e invisibile: percepire la città tra descrizioni e omissioni. Catania: AISU, 2013b.

RUFINONI, M. R., MARIANO, A. C. P., ASSIS, B. A. S., MARCOLINO, E. C., SANTOS, G. R. Patrimônio Edificado na Mooca: inventário e investigação. Acordo de Cooperação Técnica com o DPH-PMSP para a elaboração de inventários de bens culturais em São Paulo. Relatório Final. São Paulo: EFLCH-Unifesp, 2013.

SALMONI, A., DEBENEDETTI, E. Arquitetura Italiana em São Paulo. São Paulo, Perspectiva, 1981.

SÃO PAULO (Cidade). Lei 16.050 de 31 de julho de 2014. Plano Diretor Estratégico.

. Lei nº 13.430 de 13 de setembro de 2002. Plano Diretor Estratégico.

SÃO PAULO (cidade). EMURB. Galpões industriais significativos. São Paulo: EMURB, 197?.

. SMC / DPH. Patrimônio ambiental Zona Metrô Leste. São Paulo: SMC/DPH, 1978.

. SMC / DPH. Inventário Geral do Patrimônio Ambiental, Cultural e Urbano de São Paulo (IGEPAC-SP) São Paulo: SMC / DPH, 1987.

. SMC / DPH. Ofício nº 070 / DPH.G / 2012. Ref.: Cooperação técnica para realização de inventários de bens culturais - Brás e Mooca.

. SMC / DPH. Estudo para o tombamento do Patrimônio Industrial na orla ferroviária em torno da Estação da Mooca. Autoria: THOMAZ, Dalva; GIANNECCHINI, Ana Clara e ARRUDA, Valdir. São Paulo: SMC / DPH, 2007a.

. SMC / DPH. Re-Estudo da Área Envoltória dos galpões industriais em torno da Estação da Mooca. Autoria: THOMAZ, Dalva e GIANNECCHINI, Ana Clara. São Paulo: SMC / DPH, $2007 b$. 
SMC/ CONPRESP. Estudo das Zonas Especiais de Preservação Cultural. Processo: $2004-0.297 .171-6$

. SMC / CONPRESP. Processo n. $2006-0.111 .388-4$

. SMC/ CONPRESP. Resolução 14/07. Conjunto dos Edifícios Industriais da Mooca.

. SMC / CONPRESP. Resolução 05/10. Tombamento Chaminé da União.

\section{Recebido}

08/03/2016

Aprovado

16/06/2016 